\title{
浅析建筑装配式大跨度预应力混凝土钢管桁架叠合板的 研究与应用
}

\author{
刘 壮* 陈一鸣 孙世鹏 李鹏斌 \\ 中建八局第二建设有限公司，山东 250014
}

摘 要: 我国近几年主推装配式建筑, 装配式建筑成为了建筑行业的主力军。结构构件在工厂内预制, 现场湿作 业相对减少, 该结构构件的质量保障程度得到提高, 施工现场的污染, 包括噪声、扬尘及水资源等, 都有较显著的降 低。经过施工现场实践发现, PK预应力叠合板底有效减少了板底支撑的设置, 部分小跨度楼板可无支撑。通过计算发 现，预应力的存在使得PK预应力叠合底板实现了自支撑效应。这些特征使得该类型板的施工具有先进性。

关键词: 装配式; 预应力; 钢管桁架叠合板

\section{Research and Application of Prefabricated Large-Span Prestressed Concrete Steel Pipe Truss Laminated Plate in Buildings}

\author{
Zhuang Liu*, Yi-Ming Chen, Shi-Peng Sun, Peng-Bin Li
}

The Second Construction Limited Company of China Construction Eighth Engineering Division, 250014, Shandong, China

\begin{abstract}
In recent years, China has mainly promoted prefabricated buildings, and prefabricated buildings have become the main force of the construction industry. The structural members are prefabricated in the factory, the wet operation on site is relatively reduced, the quality assurance degree of the structural members is improved, and the pollution on the construction site, including noise, dust and water resources, is significantly reduced. Through the construction site practice, it is found that PK prestressed laminated slab bottom effectively reduces the setting of slab bottom support, and some small-span floors can be unsupported. Through calculation, it is found that the existence of prestress makes the PK prestressed composite floor realize the self-supporting effect. These characteristics make the construction of this type of board advanced.
\end{abstract}

Keywords: Prefabricated; Prestress; Steel Pipe Truss Laminated Plate

\section{一、引言}

第二次世界大战之后, 由于欧洲大陆的建筑普遍受到战争的影响, 遭受重创, 无法提供正常的居住条件, 且劳动 力资源短缺, 此时急需一种建设速度快且劳动力占用较少的新建造方式才能满足短时间内各国对住宅的需求, 于是国 外装配式建筑开始萌生 ${ }^{[1]}$ 。

从各个国家装配式建筑发展来看, 都有一条清晰的时间线, 我国装配式建筑虽然才刚刚起步, 但是有着国外先进 的技术和成功的经验, 我们也可以少走弯路, 大力促进装配式建筑发展, 这不仅是一条建筑方式的变革之路, 也是一 条绿色环保的长远发展之路。

\section{(一) 国家相关政策}

为贯彻落实国办发 [2016]71号文件大力发展装配式建筑的实施意见, 装配式建筑应符合国家和山东省《装配式建 筑评价标准》（GB/T51129-2017）（DB37/T5127-2018）的基本规定, 其中装配式建筑单体装配率要达到50\%以上; 本项目结构形式为框架结构，根据《装配式建评分标准》（GB/T51129-2017）单体装配率不低于50\%。

*通讯作者: 刘壮, 1983年7月, 男, 汉族, 山东潍坊人, 就职于中建八局第二建设有限公司, 中级建筑师, 本 科。研究方向：建筑超高层。 


\section{(二) 工程概况}

本项目为历城区市民中心项目综合文化中心二期，位于山东省济南市世纪大道以南，唐冶东路以西，总建筑面积 8.4万平方米。包含档案库房, 方志及组织部库房, 区情展示, 查档大厅, 老年活动, 妇女儿童活动, 培训, 健身等。 其中二层至屋面层为预应力混凝土钢管析架叠合板，为满足使用要求跨度多为 8.2 米大跨度，面积约 4 万平。

\section{二、装配式建筑常见的楼板对比分析}

(一) 主要类别

目前, 国内使用的装配式楼板主要有钢制楼承板、预制混凝土楼板、钢筋混凝土桁架叠合板、预应力混凝土钢筋 桁架叠合板、PK预应力混凝土钢管桁架叠合板。

(二) 优劣势对比

1. 钢制楼承板对比

钢制楼承板, 优点是自重轻 (如图1所示) 、施工速度快, 是钢制楼承板的一大亮点; 缺点是刚度大, 如果要在 大跨度中应用, 需要增加波高, 将造成钢筋很难布置, 混凝土用量增加; 在民用建筑中由于底面是型钢材质, 需要做 吊顶处理 ${ }^{[2]}$ 。在进行混凝土浇筑的过程中容易漏浆, 造成楼承板表面观感差, 在使用中还发现, 随着时间的推移, 钢 制楼承板的挠度增大, 容易变形。
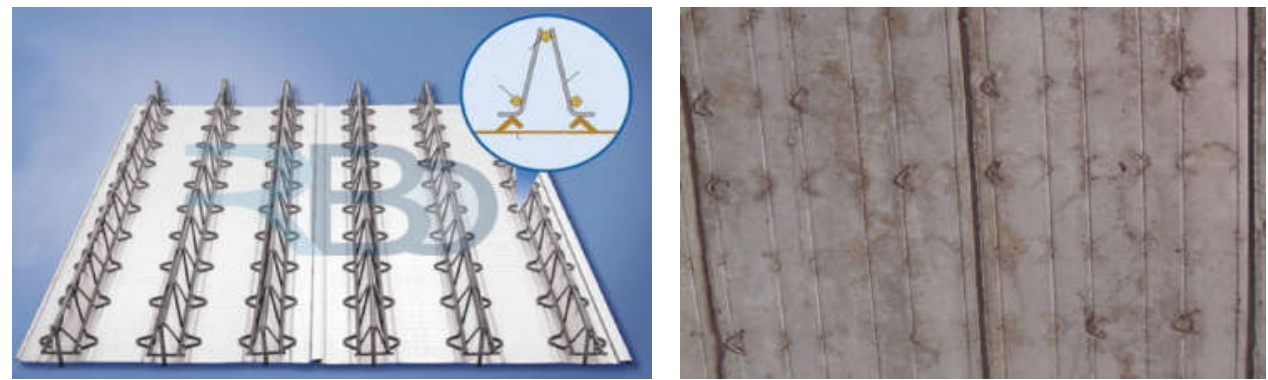

图1 钢制楼承板

2. 预制混凝土楼板对比

预制混凝土楼板具有跨度大、刚度高、施工效率高、经济性好等优点。缺点是钢筋配筋单向化, 穴余度差; 支座 适合较接形式，难以形成刚接；预制板厚、自重大，影响层高；整体性差（如图2所示），抗震性能较弱。
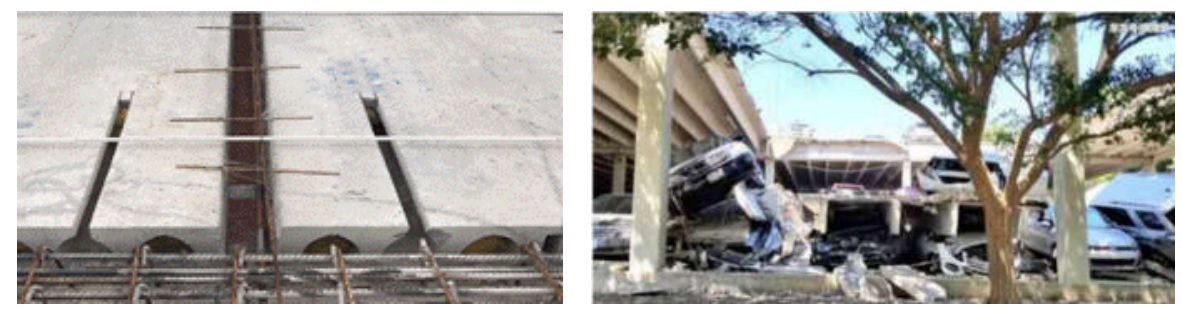

图2 预制混凝土楼板

3. 钢筋混凝土桁架叠合板对比

钢筋混凝土桁架叠合板, 厚度较厚, 规范规定厚度在 $60 \mathrm{~mm}$ 以上, 再加现浇层 $80 \mathrm{~mm}$, 造成普通跨度 ( $\leqslant 5$ 米) 房间叠合后整体厚度大于 $140 \mathrm{~mm}$ 。目前国内现浇板的厚度普遍在 $120 \mathrm{~mm}$ 左右, 直接造成结构自重增加 $15 \%$ 左右 ${ }^{[3]}$; 现 场架体布置，支撑普遍在1.2 1.5 米左右（如图3所示），相比于现浇板系统支撑体系不相上下。
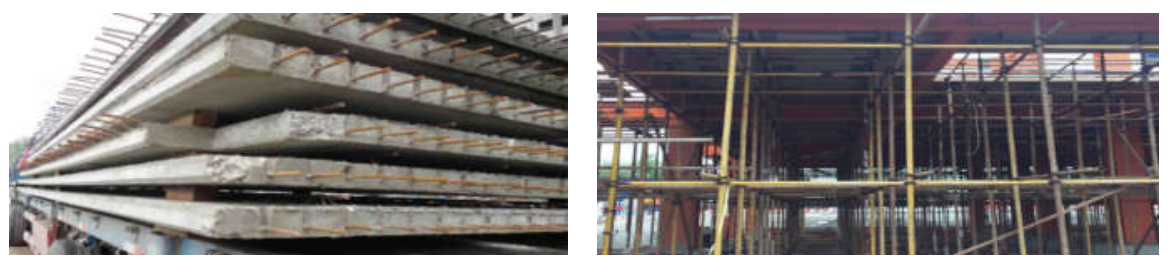

图3 钢筋混凝土桁架叠合板

板缝多、现浇带多。根据规范, 钢筋混凝土叠合板必须进行拉缝才能形成双向板。而且板缝不能位于跨中, 从而 
使每个房间的板缝多于两条 ${ }^{[4]}$ 。若进行并缝密拼处理, 后浇层厚度须大于 $2 \mathrm{~h} / 3$, 从而又增加了结构自重。拼接缝宽度 在200 $300 \mathrm{~mm}$, 在进行现浇段施工时, 要进行吊模或者增加模板支撑。当遇到横梁时被迫截断, 梁两侧的标高很难 控制。

4. 预应力混凝土钢筋桁架叠合板对比

预应力混凝土钢筋桁架叠合板, 优点是厚度小, 一般厚度在 $40 \mathrm{~mm}$ 左右 (如图4所示), 结构自重轻, 板无现浇 带, 减少漏浆情况。缺点是跨度小, 所能承受的承载力较小。
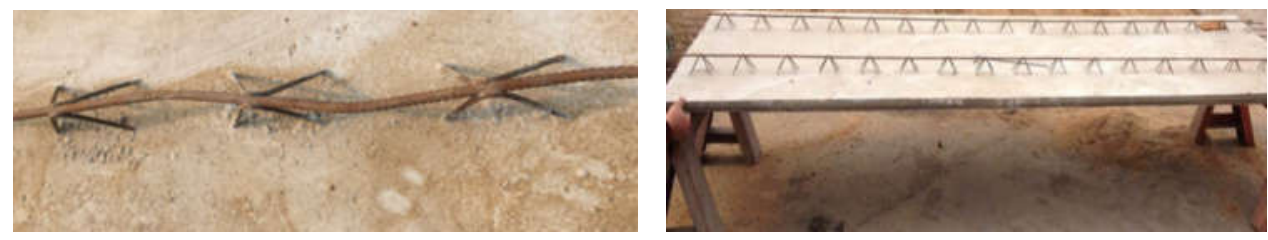

图4 预应力混凝土钢筋桁架叠合板

5. PK预应力混凝土钢管桁架叠合板优势

PK预应力混凝土钢管桁架叠合板 (如表1), 厚度 $35 \mathrm{~mm}$ 左右, 叠合后 $110 \mathrm{~mm} \sim 125 \mathrm{~mm}$ 左右, 极大减轻结构自 重; 支撑少, 支撑间距可达4米; 没有补空板, 主受力方向钢筋为预应力钢筋, 横向钢筋施工时后穿, 形成双向板; 一面出胡子筋，安装方便 ${ }^{[5]}$; 刚度可调节，不开裂。

表1 预应力混凝土钢管桁架叠合板跨度对比

\begin{tabular}{|c|c|c|c|c|}
\hline \multicolumn{5}{|c|}{ 跨度对比 } \\
\hline 名称 & 小跨度 & 中跨度 & 大跨度 & 超大跨度 \\
\hline 跨度 & $\leqslant 4.2 \mathrm{~m}$ & $4.2 \mathrm{~m} \leqslant$ 跨度 $\leqslant 6 \mathrm{~m}$ & $6 \mathrm{~m} \leqslant$ 跨度 $\leqslant 9 \mathrm{~m}$ & $9 \mathrm{~m} \leqslant$ 跨度 $\leqslant 15 \mathrm{~m}$ \\
\hline 板厚度 & $110 \mathrm{~m}$ & $120 \mathrm{~m} \sim 160 \mathrm{~m}$ & $160 \mathrm{~m} \sim 250 \mathrm{~m}$ & $\geqslant 220$ \\
\hline 优势 & 减轻结构自重, 较少成本 & 刚度好, 韧性好, & 次梁根数减少, 增大净高 & $\begin{array}{l}\text { 预应力筋可代替同方向梁的底部第一, 减少用钢量, 避免支座梁筋 } \\
\text { 碰撞, 提升吊装效率 }\end{array}$ \\
\hline
\end{tabular}

由于采用预应力技术, 上部受压区采用钢管桁架（如图5所示）, 钢管内注人砂浆, 保证了在用钢量最小的情况 下有足够的刚度, 刚度好、可悬挑; 板幅大、自重小, 最大可做到 $3 \times 12$ 平方米, 容重仅为 85 千克/平方米左右, 极大 地提高了生产、运输、吊装效率。
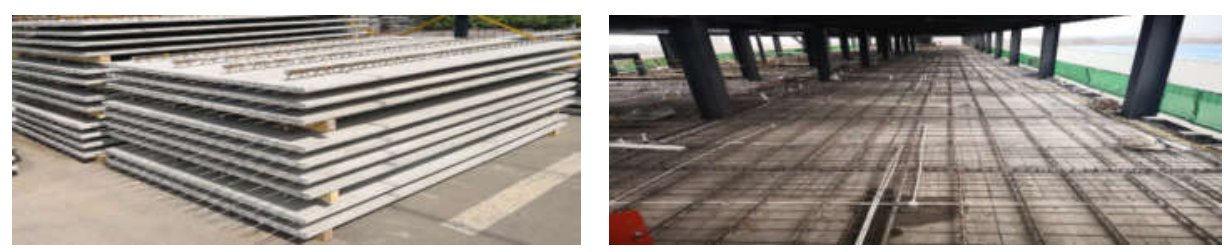

图5 预应力混凝土钢管桁架叠合板方便施工

经过对比分析发现，pk板中存在预应力短边无胡子筋，可以减少或者取消现浇带，减少漏浆的情况，方便施工。 因为PK预应力混凝土钢管桁架叠合板附加预应力，所以自重减轻，减少支撑，增加结构安全性。

(三) 试验对比

经过有限元计算模型板底受拉损伤分析，在预制底板上形成了明显的塑性铰线，是典型的双向受力（如图6所示）。
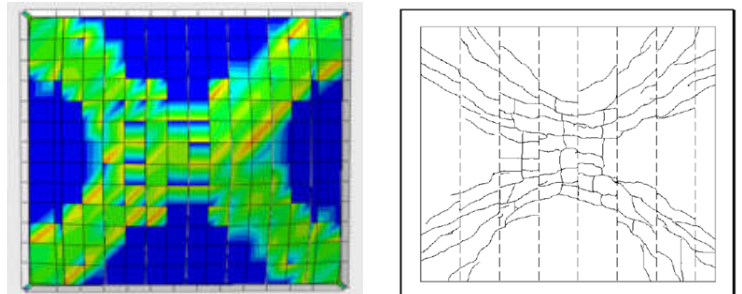

图6 有限元分析

受力双向性与有限元分析如下所述。 
1. 预应力底板+普通钢筋桁架, 板尺寸 $3.3 \times 1 \mathrm{~m}$, 板厚 $40 \mathrm{~mm}, 10$ 根 $\varphi 5$ 预应力筋, 桁架上弦钢筋为 $\varphi 8$ 三级钢, 混凝 土采用 $\mathrm{C} 40$, 在中间不设支撑状态下, 加载至 $1 \mathrm{KN} / \mathrm{m}^{2}$ 无开裂, 跨中总挠度 $\mathrm{L} / 279$ 加载至 $1.5 \mathrm{KN} / \mathrm{m}^{2}$ 板下挠度严重, 跨中 上弦钢筋弯曲, 失去承载力, 无法满足施工要求。

2. 预应力底板+矩形钢管桁架 (管内填微膨胀高强砂浆), 板尺寸 $3.9 \times 1 \mathrm{~m}$, 板厚 $30 \mathrm{~mm}, 10$ 根 $\varphi$ 预应力筋, 桁架 上弦为 $50 \mathrm{~mm} \times 100 \mathrm{~mm}$ 矩形钢管内填砂浆, 混凝土 $\mathrm{C} 40$ 。中间不设支撑状态下, 加载至 $3 \mathrm{KN} / \mathrm{m}^{2}$ 时出现裂缝, 跨中挠度 $15 \mathrm{~mm}$ (即 $1 / 250 \mathrm{~L}$ ), 加载至 $6 \mathrm{KN} / \mathrm{m}^{2}$ 时, 挠度加大, 跨中上弦钢管鼓曲, 钢管桁架腹筋与混凝土底板针固良好, 未有 拔出现象，满足施工要求，但制作成本高。

3. 预应力底板+钢管桁架 (管内填微膨胀高强砂浆) 板长 $3.600 \mathrm{~m}$, 板宽 $1 \mathrm{~m}$, 平均板厚 $35 \mathrm{~mm}$, 预应力筋面积 157 $\mathrm{mm}^{2}$, 混凝土采用 $\mathrm{C} 40$, 外加荷载, $2.5 \mathrm{KN} / \mathrm{m}^{2}$ 底板跨中位移值 $14 \mathrm{~mm}$ (即 $1 / 250 \mathrm{~L}$ ), 外加荷载, $2.5 \mathrm{KN} / \mathrm{m}^{2}$ 底板跨中位 移值 $14 \mathrm{~mm}$ (即 $1 / 250 \mathrm{~L}$ ), 加载至 $5.45 \mathrm{KN} / \mathrm{m}^{2}$ 时, 挠度加大, 跨中钢管鼓曲, 钢管桁架腹筋与混凝土底板针固良好 (如 图7所示），未有拔出现象，满足施工要求，制作成本下降。

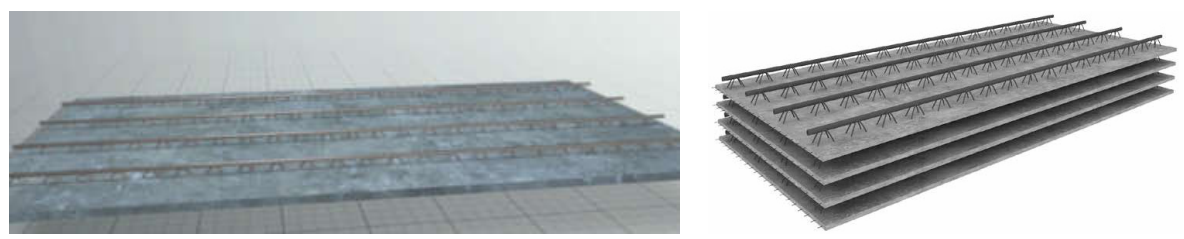

图7 预应力混凝土钢管桁架叠合板模型

4. 板尺寸 $4.55 \times 2.1 \mathrm{~m}$, 板厚 $35 \mathrm{~mm}, 34$ 根 $\varphi 5$ 预应力筋, 混凝土 $\mathrm{C} 40$, 当中间不设支撑时: 挠度 $18 \mathrm{~mm}($ 即 $1 / 250$ $\mathrm{L}$ ) 时, 加载为 $2.10 \mathrm{kN} / \mathrm{m}^{2}$, 当中间增设 1 道支撑: 继续加载至 $7.67 \mathrm{kN} / \mathrm{m}^{2}$ (1.3倍承载力荷载值) 时, 第一跨挠度下降 1 $\mathrm{mm}$, 第二跨挠度下降 $2 \mathrm{~mm}$, 无裂缝。

5. 板尺寸 $8.020 \times 1.0 \mathrm{~m}$, 板厚 $40 \mathrm{~mm}, 30$ 根 $\varphi 5$ 预应力筋, 混凝土 $\mathrm{C} 50$, 本次试验最大挠度 $4 \mathrm{~mm}$ 时, 加载为 $13.36 \mathrm{kN} /$ $\mathrm{m}^{2}$, 挠度下降 3.22 , 满足规范要求。

经过试验与有限元分析对比, 因为预应力混凝土钢管桁架叠合板厚度小, 制作成本低。同等条件下施加荷载, 预 应力混凝土钢棍桁架叠合板挠度变形更低，更不易破坏。所以预应力钢管桁架叠合板更符合本项目的设计施工要求。

\section{三、结束语}

通过实验发现预应力混凝土钢管桁架叠合板制作成本低，同条件下承载力高，能在大跨度结构中体现其超常规的 特性。

预应力混凝土钢管桁架叠合板双面出筋, 减低运输成本, 减少物料堆放场地。在施工过程中, 由于现浇截面的减 少, 减少了水泥浆的渗漏。提前施加预应力, 避免在运输以及吊装的过程中出现裂缝, 在安装的过程中, 可以减少或 取消下部支撑，降低施工难度，减低施工工期从而降低施工成本。能更有效地助推建筑业的发展。

\section{参考文献:}

[1]朱义铁.大跨度预应力混凝土梁高大模架安全设计与施工[J].中国安全生产科学技术, 2010,6(2):127-131.

[2]杨春, 吴宏伟, 莫庭威, 蔡健, 吴轶, 左志亮, 陈庆军, 潘广斌, 钢管混凝土斜柱转换结构模型振动台试验研究 [J]. 西南交 通大学学报, 2021,56(3):517-525.

[3] 张霓, 郑晨阳, 赵中伟, 刘海卿, 羡丽娜.GFRP管一煤矸石混凝土一钢管空心柱轴压试验 [ J]. 建筑材料学报, 2021,24(3):571-577.

[4]赵均海, 㚞军超, 高伟琪. H型钢梁与矩形钢管混凝土柱平齐式端板单边螺栓连接节点弯矩一转角分析模型 [J]. 工程 力学, 2021,38(6):91-102.

[5]秦鹏, 周昱, 李开琼, 易伟建. CFRP约束圆钢管高强混凝土短柱轴压试验研究 [ J]. 湖南大学学报(自然科学版), 2021,48(5):47-54. 